\title{
Atividades de extensão com idosos: a experiência do grupo História de Vida
}

\author{
Extension activities with Elderly People: the experience of living History Group
}

Actividades de extensión con ancianos: la experiencia del grupo Historia de Vida

Recebido: 19/12/2013

Aprovado: 14/06/2014
Lourraine Tavares Lorena ${ }^{1}$

Álvaro da Silva Santos ${ }^{2}$

Michelle Helena Pereira de Paiva ${ }^{3}$

Carla Maria Silvano ${ }^{4}$

O envelhecimento é um processo natural acompanhado por algumas alterações. Na velhice, alguns idosos podem apresentar quadros de alterações emocionais. Atividades e grupos podem promover a saúde mental dos idosos e sentimento de bem-estar. 0 presente trabalho relata a experiência de mestrandos e acadêmicos no grupo "História de Vida" entre idosos que participam de um centro de convivência. Essa experiência faz parte de um projeto de extensão da Universidade Federal do Triângulo Mineiro (UFTM). Esta atividade teve como objetivo promover a saúde mental dos idosos, estimular o convívio entre eles e resgatar suas histórias e identidade, realizado no segundo semestre de 2013. Como resultados o grupo além de ter seus vínculos de amizades fortalecidos, teve a oportunidade de compartilhar experiências. Através das atividades que estimularam a memória autobiográfica os idosos compartilharam experiências, fortaleceram seus vínculos de amizade e reviveram acontecimentos do passado, ressignificando suas vidas.

Descritores: Envelhecimento; Idoso; Promoção da saúde; Saúde mental.

Aging is a natural process accompanied by some alterations. In old age, some elders may have pictures of emotional changes. Activities and groups can promote elders' mental health and feeling of welfare. This paperreports the experience of masters and academics in the "History of Life" group among elders who attend a daycare center. This experience is part of a project an extension project of the Federal University of TrianguloMineiro (FUTM), Uberaba, Minas Gerais, Brazil. This activity aimed to promote the mental health of the elderly, stimulate interaction between them and rescue their stories and identity, during the second half of 2013. As a result the group, besides having strengthened bonds of friendship, had the opportunity to share experiences. Through activities that stimulated autobiographical memory, seniors shared experiences, strengthened their bonds of friendship and relived events of the past, giving new meaning to their lives.

Descriptors: Aging; Aged; Health promotion; Mental health.

El envejecimiento es un proceso natural acompañado de algunos cambios. En la vejez, algunos ancianos pueden tener trastornos emocionales. Por lo tanto, algunas de las actividades y los grupos pueden promover la salud mental de las personas mayores y el sentido de bienestar. En este trabajo se presenta la experiencia de los estudiantes de maestria y academicos en el "Grupo Historia de Vida" entre los usuários de um centro de convivencia. Esta experiencia es parte de un proyecto de extensión de la Universidade Federal do Triângulo Mineiro (UFTM), Uberaba, Minas Gerais, Brasil. Esta actividad tuve por objetivo promover la salud mental de las personas mayores, estimular la interacción entre ellos y rescatar sus historias y sus identidades, llevado a cabo en la segunda mitad de 2013. Como resultado, el grupo, ademas de tener fortalecido sus amistades, tuvieron la oportunidad de compartir experiencias. A través de las actividades que estimulan la memoria autobiográfica, los ancianos tuviéron experiencias compartidas, el fortalecimiento de los lazos de amistad y reviviran los acontecimientos del pasado, resignificando sus vidas.

Descriptores: Envejecimiento; Anciano; Promoción de la salud; Salud mental.

\footnotetext{
${ }^{1}$ Acadêmica de Enfermagem, quinto período - Universidade Federal do Triângulo Mineiro (UFTM).

${ }^{2}$ Enfermeiro. Pós-Doutor em Serviço Social. Doutor em Ciências Sociais. Professor Adjunto III e Docente junto ao Programa de Pós Graduação Estrito Senso em Atenção à Saúde da UFTM. alvaroenf@hotmail.com

${ }^{3}$ Terapeuta Ocupacional. Especialista em Saúde do Idoso na modalidade Residência Integrada Multiprofissional em Saúde. Mestranda do Programa de Pós-Graduação Estrito Senso em Atenção à Saúde da UFTM. mhppaiva@gmail.com

${ }^{4}$ Enfermeira. Especialista em Saúde do Idoso na modalidade Residência Integrada Multiprofissional em Saúde. Mestranda em Ciências da Saúde no Instituto de Assistência Médica ao Servidor Público Estadual - IAMSPE cm.silvano@hotmail.com
} 


\section{INTRODUÇÃO}

$\mathrm{E}$ stá se vivendo no país um processo de envelhecimento, ou seja, há um aumento da expectativa de vida e em contrapartida uma diminuição do índice de natalidade. Esse quadro é devido à queda da mortalidade prematura, os avanços da medicina, as melhorias nas condições sanitárias, e das mudanças nas políticas públicas voltadas para a saúde ${ }^{1}$.

No mundo, o número de pessoas idosas aumentou para quase 810 milhões no ano de 2012, estima-se que essa cifra atinja um bilhão em menos de 10 anos e dois bilhões em 2050². Já no Brasil, o número de idosos corresponde a aproximadamente 23,6 milhões de pessoas, ou seja, $12,1 \%$ dos indivíduos apresentam idade igual ou acima dos 60 anos $^{3}$.

0 envelhecimento é um processo natural e irreversível e é acompanhado por alterações físicas, fisiológicas, psicológicas, cognitivas e sociais comuns à faixa etária. Os idosos tendem a enfrentar mais eventos de perda, como o declínio da saúde física, o afastamento do mercado de trabalho, as alterações dos papéis sociais, a perda de amigos e de pessoas da família, ou seja, eventos não controláveis, que podem prejudicar sua saúde mental.

Além disso, na velhice, alguns idosos podem apresentar quadros psiquiátricos comuns nessa faixa etária como a demência, estados depressivos ou quadros psicóticos, destacando-se a depressão que é um problema comum e preocupante entre os idosos, que pode passar despercebidos por ele e pelos familiares e levar o idoso a óbito4 ${ }^{4}$.

No caso de promoção da saúde mental ou para lidar com um trauma emocional, algumas ocupações como as atividades artísticas ou contar histórias, podem proporcionar a expressão dos estados internos e o enfretamento espiritual ${ }^{5}$.

A participação de idosos em atividades ou grupos pode proporcionar estabelecimento de vínculos, melhora da autoestima e sentimento de bem-estar.
É fundamental, portanto, refletir que envelhecimento saudável e bem-estar na velhice significam ter um bom estado de saúde física juntamente com sentimentos de respeito, segurança, oportunidade de participar da sociedade e ser reconhecido pela sua contribuição6 ${ }^{6}$.

Nesse contexto, o presente trabalho tem como objetivo relatar a experiência acadêmica de mestrandos e alunos de graduação vivenciada no grupo de história de vida entre idosos ativos que participam de um centro de convivência.

\section{MÉTODO}

Trata-se de um estudo descritivo, de abordagem qualitativa, do tipo relato de experiência. 0 qual descreve a experiência vivenciada por mestrandos e acadêmicos no projeto de extensão universitária intitulado "Educação em Saúde como Agente Promotor na Qualidade de Vida do Idoso".

Este projeto foi realizado na Unidade de Atenção ao Idoso (UAI), na cidade de Uberaba, Minas Gerais. As atividades ocorriam uma vez por semana, das $13 \mathrm{~h} 00 \mathrm{~min}$ às $17 \mathrm{~h} 00 \mathrm{~min}$ horas. 0 período de realização do projeto se deu entre os meses de junho a novembro de 2013, durante o projeto de extensão universitária da Universidade Federal do Triângulo Mineiro (UFTM).

0 projeto contava com participação de 15 idosos e envolveu a atuação de mestrandos e acadêmicos dos cursos de nutrição, enfermagem, terapia ocupacional e educação física.

0 objetivo do projeto foi promover ações de educação em saúde que contribuíssem de forma positiva para o cuidado em saúde e qualidade de vida dos idosos. 0 mesmo era composto por quatro grupos de atividades: "História de Vida", "Cozinha Saudável”, "Expressão Corporal” e "Atividade Física".

Antes de dar início aos grupos de atividades do dia, era realizada uma palestra participativa com dinâmicas, sendo que toda semana elencava-se um tema diferente escolhido pelos participantes. 
Nesse relato a experiência descrita será sobre o grupo "História de Vida".

\section{RESULTADOS}

O grupo "História de Vida" tinha como objetivo promover a saúde mental dos idosos, estimular o convívio entre eles e resgatar suas histórias e identidade.

Os temas abordados no grupo "História de Vida" foram: história da cidade de Uberaba, sua vinda para cidade de Uberaba, descendência familiar, história da família, história da infância e relacionamento com familiares.

Ocorreram doze encontros desse grupo. As atividades foram desenvolvidas na sala de ginástica, pela qual se realizava um círculo, de modo que todos os participantes se sentavam em colchonetes ou cadeiras. As acadêmicas responsáveis explicavam a atividade antes de iniciá-la, além disso, estas também participavam do grupo com suas histórias e deixavam os idosos participantes livres para exporem suas histórias e emoções.

Em alguns momentos foram realizados trabalhos manuais, como a confecção de um cartaz usando-se alguns recursos para ajudar na expressão dos sentimentos e da história a serem verbalizados, como desenhos, recortes de revistas, colagens e também foram feitas algumas dinâmicas. A atividade era feita de forma individual e posteriormente socializada para todo o grupo.

No início os participantes estavam inseguros em compartilhar suas histórias, mas, à medida que outros encontros foram ocorrendo aumentou o vínculo e a confiança.

Quando alguém relatava sua experiência percebia-se no olhar dos outros o desejo de contar sua história, ou de dar sua opinião. Nas atividades os envolvidos interagiam, acolhiam, consolavam uns aos outros e todos respeitavam a história e o tempo do outro.

O grupo "História de Vida" era um momento em que ocorria a expressão de sentimentos dos participantes, trocas de experiências e aprendizados.

Os temas história da família e da infância foram os que os idosos mais trouxeram experiências e também lembranças que emocionava o grupo. Esses foram os primeiros temas abordados no grupo e houve expressão de choro e emoção. As histórias vivenciadas eram muitas vezes semelhantes ou tinham algo que as aproximavam seja pela distância, saudade, sofrimento entre outros aspectos, provocando um sentimento de empatia entre os idosos.

No final de cada grupo, apesar de muitas vezes estes serem regados de emoções, percebia-se um sentimento de alívio por poder expressar aqueles conteúdos muitas vezes angustiantes, tristes ou nostálgicos.

Ao término do projeto, pôde-se perceber que os participantes tiveram seus vínculos de amizades fortalecidos, e a oportunidade de compartilhar experiências e que por mais tempo que tinham de convivência existiam fatos e sentimentos que conheceram a partir do grupo "História de Vida".

\section{DISCUSSÃO}

A formação das memórias e os esquecimentos dependem de um sistema complexo, das modificações bioquímicas estruturais derivadas da síntese de novas proteínas durante e depois da formação de cada uma delas ${ }^{7}$.

Esse mecanismo é composto por três etapas: 1. codificação de informações - elas chegam ao cérebro através dos órgãos dos sentidos; 2. armazenagem das informações elas são codificadas, estruturadas e armazenadas no cérebro; 3. manutenção e recuperação das informações, transformação das informações em lembranças, passíveis 
de recuperação - a memória de longa duração, autobiográfica ${ }^{7}$.

Recordar eventos pessoais requer várias habilidades cognitivas, desde aquelas que permitem lembrar um fato pessoal até aquelas necessárias para escrever um livro contando a história de uma vida, nessa, as recordações pessoais vividas no passado e a própria história de vida constitui a memória autobiográfica ${ }^{8}$.

O grupo "História de Vida" permitiu aos idosos a estimulação da memória autobiográfica e a recordação de eventos pessoais, promovendo assim, a melhora da saúde mental, uma vez que pessoas com depressão, por exemplo, apresentam dificuldade em acessar as lembranças da memória autobiográfica. A redução da memória autobiográfica pode ser um preditor para o desenvolvimento de transtorno depressivo e transtorno de estresse pós-traumático ${ }^{9,10}$.

Esse grupo foi um espaço destinado não somente ao compartilhamento de histórias vivenciadas, mas também à expressão de estados internos. De acordo com alguns estudos um acontecimento só é mantido na memória e passível de ser recuperado se for acompanhado de uma forte carga emocional, isso implica que a lembrança foi armazenada em um momento de hiperatividade dos sistemas hormonais, ou seja, fica registrado aquilo que deixa marcas do e no mundo exterior, registra-se o que passa pela emoção, portanto, permanece na lembrança aquilo que tem ou teve um sentido ou significado ${ }^{7,11}$.

0 referido grupo proporcionou um resgate da própria história e identidade do idoso, podendo assim compreender o seu papel e trajetória e reconstruir um novo sentido para a vida. Através das atividades que estimularam a memória autobiográfica é possível reviver os acontecimentos do passado e interpretá-los de outra maneira ressignificando sua história de vida e dessa forma, encontrando uma razão para viver. Revivendo sua história, os fatos do passado provocadores de sofrimento podem ser repensados e muitas vezes interpretados como não tão sofríveis como quando aconteceram, ou até mesmo passíveis de compreensão pelo individuo.

Os seres humanos, são aquilo que recordam, memória é a aquisição, conservação e evocação das informações, dos fatos vividos por cada indivíduo ${ }^{7}$.

Após a experiência com os "Grupos de Conversa" parte de um projeto de extensão da Universidade Federal de Mato Grosso do Sul, denominado "Envelhecimento e promoção de saúde na rede de atenção básica", os pesquisadores relataram que durante os grupos ficou claro a importância do passado nas vidas dos idosos e que a emoção era a expressão da saudade que sentiam dos dias que viveram, além disso, a ressignificação das supostas perdas cognitivas da memória em ganhos afetivos e biográficos como a história de vida que remete a uma relativização das perdas e ganhos da velhice ${ }^{12}$.

A importância de se divulgar experiências como essa se dá na possibilidade de que experiências similares possam ser replicadas, na proposta de se promover a saúde mental de idosos, resgatando lembranças autobiográficas e construindo um novo sentido para sua vida.

\section{CONCLUSÃO}

Esse grupo realizado pelos mestrandos e acadêmicos foi uma oportunidade de trocas de experiências e aprendizado. 0 grupo "História de Vida" mostrou que é possível rever a própria história e dar a ela um novo significado, gerando redução da desesperança e um estímulo a continuar a viver melhor.

Espera-se que ao compartilhar essa experiência possa-se estimular a realização de mais grupos de história de vida com o intuito de promover a saúde mental de pessoas idosas, que possa servir de inspiração para pesquisadores, profissionais, familiares e cuidadores de idosos.

\section{REFERÊNCIAS}

REFACS(online)2014;2(3):408-412. 
1. Ribeiro EE. Tanatologia, Vida e Finitude. Centro de Referência e Documentação sobre Envelhecimento, da Universidade Aberta da Terceira Idade - UnATI, Universidade do Estado do Rio de Janeiro - UERJ. 2008.

2. Fundo de População das Nações Unidas (UNFPA). Envelhecimento no Século XXI: celebração e desafio. Disponível em: <http://www.unfpa.org/webdav/site/global /shared/documents/publications/2012/Por tuguese-Exec-Summary.pdf $>$.

3. Instituto Brasileiro de Geografia e Estatística (IBGE). Coordenação de População e Indicadores Sociais. Estimativas da população residente com data de referência $1^{\text {o }}$ de julho de 2010. Disponível em:

http://www.ibge.gov.br/home/estatistica/p opulacao/estimativa2011>.

4. Andrade HAS, Silva SK, Santos MIPO. AIDS em idosos: vivências dos doentes. Escola Anna Nery Revista de Enfermagem. 2010; 14(4):712-9.

5. Algado SS, Mehta N, Kronenberg F, Cockburn L, Kirsh B. Ocupational therapy intervention with children survivors of war. Canadian Journal of Occupational Therapy. 2002; 69(4):205-17.

6. Rocha IA, Braga LAV, Tavares LM, Andrade FB, Ferreira Filho MO, Dias MD et al. A terapia comunitária como um novo instrumento de cuidado para saúde mental do idoso. Revista Brasileira de Enfermagem [online]. 2009; 62(5):687-94 [citado 14-01$2014 . \quad$ Disponível em: $<$ http/www.scielo.br/scielo.php?script=sci_a rttext\&pid=S00341672009000500006\&lng= en. http://dx.doi.org/10.1590/S003471672009000500006.
7. Izquierdo I. A arte de esquecer. Cérebro, memória e esquecimento. Rio de Janeiro: Vieira \& Lent, 2004.

8. Gauer G, Gomes WB. Recordação de Eventos Pessoais: Memória Autobiográfica, Consciência e Julgamento. Psic.: Teor. e Pesq., 2008; 24(4):507-14.

9. Kleim B, Ehlers A. Reduced autobiographical memory specificity predicts depression and posttraumatic stress disorder after recent trauma. Journal of Consulting and Clinical Psychology. 2008; 76(2):231-42.

10. Sumner JA, Griffith JW, Mineka S, Rekart, SM, Zinbarg RE, Craske MG. Overgeneral autobiographical memory and chronic interpersonal stress as predictors of the course of depression in adolescents. Cognition and Emotion. 2010; 25(1):183-92.

11. Brandão VMAT. Memória (auto) biográfica como prática de formação. Revista @ambiente educação. 2008; 1(1)1-17. Disponível: http://www.cidadesp.edu.br/ old/revista_educacao/index.html.

12. Combinato DS, Vecchia MD, Lopes EG, Manoel RA, Marino HD, Oliveira ACS, Silva KF. "Grupos de conversa": saúde da pessoa idosa na estratégia saúde da família. Psicologia \& Sociedade. 2010; 22(3):558-68.

\section{CONTRIBUIÇÕES}

Os autores tiveram iguais contribuições nas etapas da produção do manuscrito. 